\title{
Assessing the Long-Term Impact of a Consistent Advertising Campaign on Consumer Memory
}

\author{
Kathryn A. Braun-LaTour, University of Nevada Las Vegas \\ Michael S. LaTour, University of Nevada Las Vegas
}

\begin{abstract}
How effective is an advertising campaign that has consistently used the same theme since consumers' early childhood? To answer that question one has to consider the effect the campaign has had on consumers' memory. This research begins by discussing the structure of memory and schematic processes that occur when similar or related information is presented over time. Evidence is reviewed which suggests that early exposure would be critical in the brand schema's development. An experiment that tests the strength of the brand schema in a competitive environment and a survey that explores the importance of time of initial exposure to present-day affect and attitudes toward the brand are presented. The implications of the results for advertising research and practice are then discussed.
\end{abstract}

Although most advertising researchers assume that a consistent long-term advertising campaign is an effective way to present a solid enduring image to consumers and maintain a long-term relationship, there is little published research on the effectiveness of such a strategy. This is partly due to the fact that most advertising studies, in an attempt to control for "background knowledge," focus on new ads or fictitious brands to isolate their variables of interest (Keller 1993 ). In addition, while the adage may be to seek a long-term consistent campaign, the actual practice of such a strategy by advertisers is quite rare. Only a few such long-standing campaigns come immediately to mind-the Maytag repairman, MetLife and the Charlie Brown gang, the Energizer Bunny, for example. More commonplace is the switching of campaigns - or even advertising agencies - to gain interest among consumers.

Understanding the effect of prior advertising exposure, especially long-term, is an important area of research for marketers interested in pursuing consumer relationships. Although some studies have examined multiple exposures to a single message (e.g., Cacioppo and Petty 1979; Mitchell and Olson 1981; Schumann, Petty, and Clemons 1990), those studies have produced mixed results, and have 
included only a limited number of exposures presented over a relatively short time period. A view of the underlying psychological processes is necessary to understand how prior exposure affects how subsequent advertising is interpreted. For instance, Edell and Keller (1989) found that while there was no difference in the amount of cognitive responses or attitudes when an ad was seen one time or two times, there was a change in the memory structure. We suspect even greater effects on memory if the ad had been shown over years and years of viewing.

Two issues are of interest to advertisers interested in long-term effects: First, many different types of information can be stored in memory and may exhibit different memory processes; second, the amount and nature of information for other advertised brands in memory can produce interference effects. A more dynamic and comprehensive view of memory is therefore needed. Toward that end, we begin by briefly reviewing different types of memory and discuss schematic processes that occur over multiple presentations of similar material. We then present evidence from the psychological literature as to why early childhood exposure to advertising might be especially important in the formation of the brand schema.

There are no direct tests to determine the strength of a brand schema. However, as schemas are consistent with a reconstructive view to memory, memory errors may occur, and these errors can reveal the inherent strength of the long-standing campaign. For instance, a common memory error is source confusion: When seeing an ad that is very similar to one of a well-established brand campaign, consumers may believe they have seen an ad for the already established company. In an experiment, we test the strength of a brand schema created over time with consistent advertising using a real-life situation: MetLife as the company that has featured Peanuts characters since our participants' early childhood; Hallmark as the new user of the Peanuts characters.

Our interest was determining whether our participants' brand schema of MetLife would influence how they remembered the Hallmark commercial, or if the Hallmark commercial would interfere with memory of MetLife's ad. We investigate whether it was the early childhood exposure of the MetLife campaign that led to strong associations to MetLife, in both the experiment and a survey. We discuss the implications of this research for those studying the long-term effects of advertising, as well as the importance of beginning the brand relationship early to develop the brand schema. 


\section{Background}

\section{Dynamic Memory Processes}

Memory is a complex process. To simplify the study of memory, psychologists have segmented memory based on time (short-term, long-term), content (episodic, semantic, procedural), and consciousness (implicit, explicit). Although this segmentation certainly allows more scrutinized study of a particular domain, what is often overlooked is how these processes interact (see Schacter 1996). For instance, seeing an ad both creates an episodic memory of that experience and forms semantic associations to the brand, which first reside in short-term storage and may well go into longer-term storage. That information may be accessed through explicit measures of memory (recall, recognition), or, if received in a low-involvement format, it may be better accessed through implicit measures (such as reaction time tests, or indirect measures of association). What makes the study of memory even more complex is the recognition, albeit new, by advertising researchers (Braun 1999), that memory for the advertising information itself is dynamic and subject to change. To contrast this new dynamic with the old static view of memory, consider the following example: In the past, researchers believed that memory for an ad created a separate memory trace that decayed over time, and failure to remember the ad was due to the inability to find the right cue to access its content (Keller 1987). The new view is that the memory for the ad interacts with other information in storage, such as other remembered ads, personal experience with the advertised brand, and word-of-mouth information about the brand (Edell 1993).

One of the prominent models that describes this evolving process is the spreading activation model of memory (Collins and Loftus 1975; Collins and Quillian 1969). In this model, concepts or ideas are linked via a network. As one concept is activated, it spreads energy to other related concepts. For instance, when a consumer sees an advertisement, concepts related to the brand become active, as do concepts related to the execution, such as the spokesperson or message. The more repetitions of a given linkage, the stronger and more automatic the association between the concepts becomes.

Memory is a highly efficient system. When similar information is presented over time, that information is collapsed together. For instance, we may not remember every time we saw a MetLife commercial; instead, we more generally remember that those ads had featured the Charlie Brown gang, due to the continuous activation of that linkage from the advertising campaign. Ideally, as the general purpose of the advertisements is to add to consumer's knowledge about the brand, those episodic events become linked in storage with other information related to the brand. The resulting network is 
referred to as a brand schema or mental model (Thorndyke 1984). These schemas influence how we process incoming information; for instance, they guide our recognition process by providing expectations of what should occur. These schemas include both explicit knowledge of the brand (e.g., consumers may recall their past experience with a MetLife salesperson) and also implicit, more unconscious associations to the brand (e.g., they may have a positive affect gained through years of exposure). Researchers find that explicit memory for particular advertising elements tends to be less stable than the underlying associations formed in the schema, which is more of an implicit (unconscious) memory (Edell 1993).

Advertising repetition is thought to build on the schematic structure, making the brand schema and its associated linkages stronger (Edell 1993). There are advantages for a company that has a wellestablished brand schema, mainly the likelihood that subsequent advertising will be better remembered (Edell and Keller 1989). An advertisement that has been seen before activates the brand schema in memory, which, in turn, provides a stronger memory trace for that advertisement. We thus offer the following hypothesis:

Hypothesis 1: Consumer recall and recognition will be better for a brand whose schema has been established with a continuous advertising campaign compared with a new brand using a similar message strategy.

The alternative hypothesis, based on the old view of memory, is that each advertisement should have its own memory trace, and prior experience of seeing past advertisements should not matter.

Our schematic knowledge about brands is built over time, but not all elements that compose a schema are created equal. Early childhood exposure is the most critical in establishing the guidelines for the schema (Kotre 1995). The next section discusses the importance of reaching the market early with one's advertising message.

\section{Childhood Exposure}

Children learn about brands from parents, peers, and the media. Even before they can read, children as young as two or three years of age can recognize familiar characters or products (Derscheid, Kwon, and Fang 1996; Haynes et al. 1993). By preschool, children begin to recall brand names from seeing them advertised on television, especially those that are associated with salient visual cues such as colors, pictures, or cartoon characters (Macklin 1985).

Children are generally more susceptible to advertising than are other age groups (Macklin 1 985), and early research sought to protect them from advertising messages. Thorson (1990) concludes 
her review of advertising's influence on consumers by asserting that much of its impact may come from the long-term accumulation of input from the hundreds or thousands of ads to which we are exposed as children. Thus far, there is little, if any, research examining the role of reaching consumers at a young age with a message intended to influence behavior much later in life (Mizerski 1995).

We propose that a company that establishes its brand schema early in consumers' childhood benefits not only from the repetition of consumers seeing the ads over the years, but also because consumers' viewing the ad early helps establish the criteria for the brand and product schema (Kotre 1995). Ceteris paribus, when consumers' brand schemas were created in childhood, their network of associations will include aspects related to those early years, thus providing them with positive affect or nostalgia (Holbrook and Schindler 1996). We therefore propose the following hypothesis:

Hypothesis 2: All else held constant, consumers who have received a consistent ad message begun early in their childhood, rather than later in life, will hold more favorable affective reactions to the brand.

Consumers who have seen the ad since childhood will harbor more childhood associations with the established brand and message characters than they will with a brand attempting to use these new characters in their advertising. The alternative hypothesis is that time of initial exposure should not matter and that any affect created toward the brand is due to the mere repetition of advertisements (e.g., Zajonc 1968) or the "feeling of familiarity" created via multiple exposures (Law 2002). In addition, according to the old view of memory, which views advertising memory as decaying over time, consumers ought not to have any memory, either explicit or implicit, of childhood exposures to the brand. Thus, under that view, a brand that has tooted itself in consumers' childhood should have no difference in memory associations than a brand that has just begun a new campaign.

We admit that testing how well a brand schema has developed is not an easy task. While Fisher and colleagues (1991, p. 3147) argue "brand awareness created in childhood can be the basis for product preference later in life," they also believe it is impossible to predict the advertising-induced recognition on future behavior. The strength of the brand schema may not be evident until competitive forces come into play and attempt to interfere with the established memory schema.

\section{Source Confusion}

As Eveready Battery gears up for a new round of TV spots featuring the Energizer Bunny, the number one battery maker is facing ... consumer confusion over which brand the bunny actually promotes. Duracell contends that up to 40 percent of consumers who recall the initial bunny campaign believe it is promoting Duracell, not Energizer. (Liesse 1990) 
The Eveready situation is an example of source confusion, a type of memory error. In most situations, the ad claim content (in the above example, the bunny) is remembered first, and the source (the advertiser, Energizer) is identified later (Pham and Johar 1997). Source memory can be extremely fallible. Indeed, consumers can succumb to source confusion errors, especially when there is a high degree of similarity in the messages. According to Johnson, Hashtroudi, and Lindsay (1993, p. 6), "the more similar the memory characteristics from two or more sources, the more difficult it will be to specify the source correctly." This can be explained through the activation model-seeing similar messages, such as advertising, activates similar linkages in memory. When later recalling the brand associated with the advertising, the consumer recalls the brand with the strongest linkage to the associated network.

There are factors in the environment that can enhance source confusion, such as the amount of advertising from the competition. Though not studying source confusion per se, some classic literature on competitive interference (Burke and Srull 1988; Keller 1987, 1991; Kent and Allen 1994) has found that a competitor's ad can reduce recall of one's brand name and claims. Not all brands are thought to be affected equally in this interference process; brands with a richer memory trace and associated brand schema are thought to be less subject to these interference effects (Alba, Hutchinson, and Lynch 1991)Meanwhile, brands that have a weak linkage between the message content and the brand may be more subject to errors. Though not yet tested directly, memory researchers Alba and Chattopadyay propose in their future research section $(1986$, p. 368) that "salience may be raised over the long-term through continuous advertising." Such salience may reduce memory errors and favor the established brand. Hence, we posit the following hypothesis:

Hypothesis 3: When memory errors occur due to source confusion, consumers will favor the established brand with a stronger brand schema associated with the message strategy.

This confusion may result in consumers falsely believing they had seen an advertisement for the established brand when they in fact had seen an ad for the new user, "forgetting" seeing the new user ad when both brands are advertised in a similar manner, or perhaps "remembering" seeing the established brand's ad during the session, when no such ad had appeared, because of exposure to the advertisement in another context (see Schacter [1996], who explains source confusion errors due to reconstructive memory processes).

We note that, thus far, research on the ability of brand familiarity (or the ability of brands with a well-established schema) to reduce interference effects has been inconclusive. Both Johar and Pham 
(1999) and Kent and Allen (1994) find that only unfamiliar brands are subject to interference. Law (1995, 2002) and McQuarrie (1998), however, find that familiar brands are not immune to competitive interference effects. Past research has only considered within-product category interference; no one has yet investigated whether cross-category usage of a similar advertising strategy can result in source confusion.

\section{Study 1}

The purpose of this research is to investigate how a consistent advertising campaign begun in our participants' early childhood has developed the brand schema and exerted an influence on how consumers perceive that brand today. As noted earlier, the effects are likely to be observed through indirect measures, as such information is more likely to be stored in implicit memory. As a means to provide insight into the issue of schema development, we begin with a survey intended to provide insight into Hypothesis 2, generational differences in initial exposure to an advertising campaign, as well as provide support for our selection of participants for our experimental investigation. In that experiment, we investigate the strength of an established brand's schema when another company uses that same character in its advertising.

\section{The Survey}

Participants

One hundred twenty-five undergraduates representing Generation X (61 male, 64 female) completed the survey as part of class credit. The average age was 21 . One hundred and two baby boomer consumers (59 male, 63 female), with an average age of 50, completed the survey in a mall intercept. The MetLife campaign was begun in 1984, so the GenXers were approximately four years old when that campaign started, and the baby boomers were well into their adulthood.

\section{Method}

Participants completed a one-page (double-sided) survey. The survey started as a generic insurance questionnaire in which respondents were to indicate whether they currently owned insurance and what brands they would include in their choice of insurance carriers. The survey then got more specific regarding MetLife, asking, for example, whether participants had previously heard of MetLife, what first comes to mind when they hear "MetLife," what age they first saw the MetLife commercials, and asking them to describe what they remember about MetLife commercials. Five 10-point items were 
used to tap the association of MetLife commercials with childhood memories and nostalgia. These included: "Rate how well you remember seeing MetLife commercials as a child"; "Rate how much you associate MetLife commercials with your childhood"; "Rate how much you associate MetLife commercials with holiday programming you saw during your childhood"; "Rate how much you associate MetLife with Snoopy and the gang"; and "Rate how much nostalgia, or feelings of warmth for the past, you have when you see 'MetLife' or their commercials." While these do not constitute formally validated scales, they do appear to have reasonable face validity and applicability for further illumination of memory content. In addition, participants indicated their attitude toward MetLife via four semantic differential scales (favorable/unfavorable, good/bad, pleasant/unpleasant, positive/negative). Via factor analysis, these attitude scales were found to be unidimensional and were averaged to form an attitude measure (Cronbach's $a=.93$ ). There were two affect-driven scales. One of these scales was the "smiley face" (Neelankavil, O'Brien, and Tashjian 1985), which, as a seven-point scale, had seven different faces, with a full frown at the left and a broad smile for the far right face. Participants were told to pick the face that represented their feelings toward MetLife. The other affect-driven scale was the "feelings thermometer" (Wilcox, Sigelman, and Cook 1989), which, at the bottom of the thermometer, had 0 degrees, to indicate a "very cold or unfavorable feeling," and at the top, 100 degrees, to indicate a "very warm or favorable feeling." These scales were found to be positively correlated $(r=.64$; Cronbach's $a=$ .72). Both scales were converted to 10 -point scales (with 10 being most favorable) and the two items were averaged to form our affect measure.

Results

We found that more baby boomers currently have their own insurance, $92 \%$ versus $36 \%$, significantly different at $\chi^{2}=72, d f=1, p<.05$, and that GenXers were more likely to freely include MetLife in their choice set of future providers, $5 \%$ versus $1 \%$, significantly different at $\chi^{2}=4.32, d f=1, p$ $<.05$. Both groups reported high awareness of MetLife: $95 \%$ for GenXers, $92 \%$ for boomers, with no significant difference. However, when asked what first came to mind when hearing the word "MetLife," GenXers were much more likely to state "Snoopy" or "Peanuts" than were boomers, 62\% versus 42\%, significantly different at $\chi^{2}=8.63, d f=1, p<.05$, and in their descriptions of the MetLife commercials they remembered, GenXers were more likely to mention Snoopy or the Charlie Brown gang than were boomers, $92 \%$ versus $70 \%$, significantly different at $\chi^{2}=12.24, d f=1, p<.05$. Although we do know the year each group was first exposed to the MetLife campaign (1984), we asked participants to recall when 
they themselves first remembered seeing a MetLife commercial; GenXers' average age was 10, boomers average age was 27 , significantly different at $t(137)=11.61, p<.05$.

Compared with boomers, GenXers reported better memory of seeing MetLife commercials as a child, $M=4.8$ versus $2.4, t(224)=7.19, p<.05$; more association to MetLife and their childhood, $M=2.4$ versus 1.6, $t(225)=2.54, \mathrm{p}<.05$; more association with MetLife to holiday programming they saw as a child, $M=2.6$ versus 2.0, $t(225)=2.01, p<.05$; more association between MetLife and Snoopy and the Charlie Brown gang, $M=7.9$ versus 6.3, $t(225)=3.55, \mathrm{p}<.05$; more favorable attitudes toward MetLife, $M=6.3$ versus $M=4.8, t(223)=4.71, p<.05$; more positive affect toward MetLife, $M=6.7$ versus 5.7, $t(219)=4.39, p<.05$; and greater intention of purchasing MetLife in the future, 4.7 versus 3.5, $t(225)=$ $3-58, p<.05$. There was no difference between age groups in terms of the warmth/nostalgia they felt: toward MetLife, $M=4.8$ for GenX, $M=4.4$ for boomers.

\section{Discussion}

The purpose of this survey was to determine whether the age of initial exposure to the MetLife campaign made a difference. If advertising works in the long run solely due to repetition effects, we would expect no difference in these generations' reactions to MetLife and its advertising, for they were both exposed to the campaign over the same number of years. However, as proposed in Hypothesis 2, we find that early exposure is critical in forming the brand schema. Generation Xers had stronger memories of the MetLife advertising, more association with MetLife and their childhood, and more positive attitudes toward MetLife than did boomers.

To more fully tap the strength of the brand schema, however, we need to test what happens when a competitor starts using a similar advertising approach. If the long-term advertising has not contributed to the brand schema, we would expect some interference in the memory of the established brand's advertising. Yet if that prior exposure has become a strong part of the brand schema, we would expect better memory for that company's commercial (Hypothesis 1), and when memory errors occur, they should favor that existing brand (Hypothesis 3).

\section{Study 2}

\section{Experiment}

The purpose of this experiment is to test how a brand using a consistent advertising campaign, MetLife, fares when another company, Hallmark, attempts to use a similar approach in their advertising. 


\section{Participants}

One hundred fifty-eight undergraduates ( 86 male, 72 female) participated in this experiment for course credit, with an average age of 21 . As mentioned previously, this age group had been exposed to (on average) the MetLife/Snoopy campaign since the age of four. The study was run in 2002 (separate from our previous survey).

Stimuli

The ads were real televised ads for MetLife and Hallmark. Each was 30 seconds long and featured Snoopy and the Charlie Brown gang. The MetLife ad was fully animated and featured an out-ofcontrol Lucy skating into Linus, Peppermint Patty, and almost into a hole in the ice, only to be saved by Snoopy. Linus says he "never realized the world was so full of hazards," and Lucy, after being saved, says, "Get Met. It pays." The Hallmark commercial begins with a (real) man taking a bowl of dog food to his dog's house. It is snowing. The house is decorated with Christmas ornaments and his dog is lying paws up, just like Snoopy. The man says, "Good grief," and then the Peanuts music is heard in the background. Animated Charlie Brown and Woodstock appear, reading a book that's free at Hallmark. We then see an animated Snoopy dancing in front of the Hallmark logo. The last shot is of the man's doghouse.

Method

Participants came to the experiment setting and watched a 20-minute clip of Seinfeld, which was taped off the air. The show features Jerry putting a Pez dispenser on Elaine's lap during George's girlfriend's piano recital. The test commercials were inputted into the breaks. After segment one, there were four commercials: one for Milky Way, one for McDonald's, the test commercial, and one for Subway (all of which were 30 seconds long). After the second segment, there were seven commercials: a movie promo for Changing Lanes, an ad for Abreva cold sore medicine, an ad for Blue Bell ice cream, the second test commercial (if there was one), an ad for Arby's, an ad for a local bank, and a promo for the Simpsons. All the commercials were 30 seconds long, except the one for the local bank and the Simpsons promo, which were 15 seconds long.

As a means to simulate real-world viewing conditions, an incidental learning procedure was used, that is, participants were not told that their memory for the ads would be tested. They were exposed to one of the following conditions: control (baseline, no target commercials seen); MetLife only (just the MetLife Snoopy commercial appeared in the first break); Hallmark only (just the Hallmark Snoopy commercial appeared in the first break); both 1 (both Hallmark and MetLife commercials, 
MetLife appearing first); both 2 (both Hallmark and MetLife commercials, Hallmark appearing first). When participants saw both target commercials, the ads were placed during different commercial breaks so as to avoid drawing attention to their similarity or the purpose of the experiment. This tactic appeared to be successful: No one was able to guess our research hypotheses. After viewing Seinfeld and before filling out the questionnaire, participants were given an unrelated 15-minute distracter task in which they viewed a government public service announcement and responded to scales rating it. Several issues were investigated in our main questionnaire: advertising memory, childhood associations, and present-day associations.

Advertising Memory: Participants were given a blank table and told to recall (list) as many of the commercials they remembered seeing within the Seinfeld program. They were asked to describe these commercials to their best ability. On the following page they were asked to identify some of the commercials that had appeared. The two target commercials (MetLife with Snoopy characters and Hallmark with Snoopy characters) were buried within a list of nine commercial descriptors as well as a misleading descriptor, "Hallmark and Carebears," to provide an additional test for source confusion.

Childhood Associations: To determine how far back their associations went with MetLife and Hallmark, participants were asked about character/spokespeople they remembered sponsoring certain brands during their childhood. Eight brands were supplied (including MetLife and Hallmark), and participants were to supply the character/spokesperson associated with each; we call this measure "Free Association of Snoopy with Childhood." Next, the interest was with what products/brands they associated with Snoopy and the Charlie Brown gang. There was a list of eight brands (including MetLife and Hallmark), and participants were to put an "X" in front of the brands they remembered being associated with Snoopy and Charlie Brown during their childhood; we call this measure "Identification of Snoopy with Childhood."

Present-Day Associations: Participants were asked to rate how much they associated certain brands and spokespeople on a scale, with 1 being "not at all" and 10 being "highly associate"; we call this "Strength of Association Between Brand and Snoopy." The final question involved making a choice between products participants did/did not associate with Snoopy and the Charlie Brown gang, which we call "Choice for Snoopy Ownership." They were asked to choose whether MetLife or Hallmark was more associated with Snoopy and the gang, and to provide a reason for their choice. 


\section{Coding Procedure}

Two independent judges looked at the advertising recall descriptions and the reasoning for choosing an association between Snoopy and either MetLife or Hallmark. For the recall statements, the judges looked at whether or not the participant mentioned Snoopy or the Charlie Brown gang as having appeared in the Hallmark or MetLife ad. They also coded what ad (when both were recalled) appeared first. For the reasoning, the judges looked at whether the participant mentioned having just seen either the MetLife or Hallmark ad, and if so, if he or she properly identified the source of the advertisement to the content. The interrater reliability was high (.9), and the two judges settled their disputes by discussing their reasons, thus coming to a joint decision.

Results

Advertising Memory: We begin with a discussion of Hypothesis 1, which posits that the prior long-term exposure of MetLife commercials should enhance memory for that company's commercial over the new user, Hallmark. Note that for some of our analysis, we will be combining groups; those results will be discussed in the text. (The raw group counts and percentages can be seen in Appendix 1.) We begin our discussion with the conditions where only one of the target ads was seen. There was significantly more recall and recognition for MetLife's commercial when it was the only target seen (MetLife-only): $78 \%$ recall of MetLife versus $56 \%$ recall of Hallmark when it is the only Snoopy ad seen (Hallmark-only group), significantly different at $\chi^{2}=3.63, d f=1, p<.05 ; 86 \%$ recognition of MetLife and Snoopy in the MetLife-only case versus 63\% recognitions of Hallmark and Snoopy in the Hallmark-only condition, significantly different at $\chi^{2}=4.88, d f=1, p<.05$. There is also greater recall of the content, Snoopy, in the MetLife-only case than in the Hallmark-only case: $96 \%$ versus $59 \%$, significantly different at $\chi^{2}=10.61, d f=1, p<.05$. These findings all suggest a benefit that MetLife had going into the studythe stronger brand schemata facilitated advertising memory for its commercial, which provides evidence for Hypothesis 1. Recall that the alternative hypothesis suggests that there should be no difference in memory for the commercials: Both were shown recently and should have a separate memory trace (if the old view of memory as a static system were correct).

When both MetLife and Hallmark are advertised, MetLife again emerges as the "winner." There is higher recall and recognition of MetLife, regardless of the order of the two commercial presentations: $81 \%$ recall of MetLife when it came first, and $83 \%$ recall of MetLife when it came second, compared with $33 \%$ recall of Hallmark when it came first, and $37 \%$ when it came second. Because there was no significant difference due to order, the conditions were collapsed, and we found greater recall for the 
MetLife ad, 83\%s than for Hallmark, 35\%, significant at $\chi^{2}=28.68, d f=1, p<.05$. There was also greater recognition for the MetLife ad. There was also no significance due to the order of presentation ( $82 \%$ for MetLife when it was presented both before and after, versus $41 \%$ for Hallmark when it came second and $39 \%$ when it came first), so the "both" conditions were collapsed, and the difference in ad type was significant at $\chi^{2}=-23.5, d f=1, p<.05$. The greater recall of MetLife provides additional support for Hypothesis 1: Prior exposures created a stronger schema that allowed the newly viewed commercial to be better remembered than a competitor using a similar, but new message strategy.

In fact, when both commercials are shown, the Hallmark ad seems to help MetLife's recall and recognition, with $78 \%$ recall when only MetLife was seen versus $83 \%$ recall in the "both" conditions, though they were not significantly different. The opposite is true in the case of Hallmark. Competition from MetLife resulted in less recall for Hallmark, with $56 \%$ recall when only Hallmark was seen versus $36 \%$ recall in the "both" conditions, significantly different at $\chi^{2}=3.48, d f=1, p<.05$. This demonstrates that MetLife did lead to inhibition of the competitor's advertising, whereas Hallmark did not, which lends support to Hypothesis 1.

The only aspect of recall in which the conditions that received both target commercials differ has to do with the order that participants recalled the MetLife and Hallmark commercials. When MetLife is shown first, it is always recalled first, which suggests that participants were using a strategy of recalling in order what they had seen. This is not the case when Hallmark appears first: Only $48 \%$ of participants recall the Hallmark ad before the MetLife one, significantly different at $\chi^{2}=4.49, d f=1, p<$ .05. This provides additional evidence of MetLife's stronger memory schema; even when MetLife appears second, it comes to mind first.

We now consider the third hypothesis, which proposes that source confusions may occur when companies utilize similar message strategies, and when they do occur, consumers will favor the brand that has a long track record of using that campaign strategy. The first thing to note is that in the baseline condition, where neither MetLife nor Hallmark ads appeared, there is no recall but some false recognition for both MetLife and Hallmark (10\% for MetLife and 3\% for Hallmark). It appears that the long-standing usage of Snoopy and the Charlie Brown gang leads to a false sense in participants that they had recently seen the MetLife commercial when, in fact, they had not. To test this, memories of MetLife (in baseline and Hallmark-only conditions) were compared with occurrence of false memories of Hallmark (in baseline and MetLife-only conditions). There was $10 \%$ false recognition for MetLife versus $1.49 \%$ false recognition for Hallmark, significantly different at $\chi^{2}=4.39, d f=1, p<.05$. This source 
confusion demonstrates the role that prior associations formed between MetLife and Snoopy have on memory, which supports Hypothesis 3.

In fact, in the condition where participants only viewed the Hallmark commercial, one participant insisted during the free recall section that they had seen a MetLife commercial, describing the Hallmark commercial in detail but attributing it falsely to MetLife. There was a greater likelihood that participants would falsely identify seeing the MetLife ad when Hallmark was actually seen than there was that they would think they saw a Hallmark ad when in fact they had seen a MetLife ad: $4.48 \%$ false recognition of MetLife versus $0 \%$ false recognition for Hallmark, significantly different at $\chi^{2}=3.87$, $d f=1, p<.05$. There is also a greater likelihood of confusion when participants see the Hallmark ad with the misleading Carebear example instead of the "true" Snoopy in conditions in which the Hallmark ad is presented than in those that do not present the Hallmark ad: $8.79 \%$ false recognition of Hallmark Carebear in Hallmark conditions (Hallmark- only and both), compared with $0 \%$ in conditions that did not present the Hallmark ad (baseline and MetLife-only), significantly different at $\chi^{2}=6.20, d f=1, p<.01$, showing that Hallmark had a weak memory link to the Charlie Brown

Another example of memory confusion occurs in the "both" conditions: Participants merged aspects of the Hallmark/ Snoopy ad into their recall of the MetLife ad. For instance, Snoopy and the doghouse were prominent in the Hallmark ad, whereas the MetLife ad featured Snoopy and the gang ice-skating (no doghouse was seen). Yet, in their recall and reasoning, many people recalled seeing the doghouse and associated it with MetLife, or they simply "forgot" seeing the Hallmark commercial (total of these errors, $37 \%$ ), thinking they had only seen a MetLife commercial. For example, some of the verbatims in the choice task included: "I don't remember any Hallmark advertising" and "I don't remember any Hallmark commercials with Snoopy characters." Both participants had seen a HallmarkSnoopy commercial less than twenty minutes earlier. These false attributions in favor of MetLife provide insight into Hypothesis 3, which postulates that a brand with a well-established history of being associated with a spokesperson or claim will be favored when source confusions occur.

Childhood Associations: The interest in this section was in gaining insight into Hypothesis 2: How far back did participants' associations with Snoopy and the companies go, that is, were they newly formed in this session or based in childhood memory? (See Appendix 2 for raw counts and percentages.) Overall, there was more remembered association to seeing Snoopy as the MetLife spokesperson during participants' childhood in the open-ended section, labeled as "Free Association of Snoopy with Childhood," where 83\% mentioned MetLife and the Charlie Brown gang/Snoopy, whereas only 19\% did so for Hallmark in the free recall task, significantly different at $\chi^{2}=120.20, d f=1, p<.05$. MetLife 
appears to have hit a ceiling, such that the incremental effect of seeing one more Charlie Brown/Snoopy ad has little effect; in the baseline condition, $80 \%$ associated MetLife more with Snoopy than with Hallmark, and in all the ad conditions, $83 \%$ indicated this association. In contrast, in the case of Hallmark, the incremental effect is larger: For those who didn't see the ad, only 7\% showed a HallmarkSnoopy association (in the MetLife-only and baseline conditions) versus $28 \%$ of those who saw the ad (Hallmark-only and both conditions) reporting such an association, significantly different at $\chi^{2}=9.24, d f$ $=1, p<.05$. So while Hallmark did not explicitly hurt the longstanding memory of MetLife's association with Snoopy in childhood, it was able to benefit from this memory by advertising with the Snoopy characters.

On another childhood measure, MetLife was found to be a brand (chosen from the list of brands) to be more associated with Snoopy and the gang, or "Identification of Snoopy with Childhood": $90 \%$ versus 56\%, significantly different at $\chi^{2}=44.56, d f=1, p<.05$. The ad exposure again benefited Hallmark, but not MetLife. For those that saw the Hallmark commercial (Hallmark-only and both conditions), $67 \%$ thought Snoopy had been associated with Hallmark products, whereas only $44 \%$ thought so if they hadn't seen the ad (baseline and MetLife-only conditions), significantly different at $\chi^{2}$ $=7.67, d f=1, p=.005$. These measures therefore provide insight pertinent to Hypothesis 2 beyond the initial survey, demonstrating that the childhood exposure to the advertising had an influence on the creation of the MetLife schema.

Present-Day Associations: Last, the interest was with what company held the strongest presentday associations to Snoopy and the gang, or "Strength of Association Between Brand and Snoopy." For MetLife, there was no significant difference across conditions: The ad did not help (nor did the Hallmark one hurt), overall $M=8.7$ on a 10-point scale where higher numbers equal greater association, compared to $M=5$ for Hallmark overall. This difference was significant, $F(1,314)=156.71, p<.05$. For MetLife, the strong brand schema created from years of advertising had already been established. That was not the case for Hallmark. The overall model was significant, $\mathrm{F}(3,153)=3.49, p<.05$, and comparisons between the groups where the Hallmark ad was seen (Hallmark-only and both conditions) resulted in more association than when the ad was not seen (baseline and MetLife-only), $M=5.74$ versus $M=4.10$, significantly different at $F(1,155)=9.9, p<.05$. The difference in perceived association to Snoopy between MetLife and Hallmark was also significant, $F(3,153)=3.56, p<.05$, and follow-up tests revealed that those who saw the Hallmark ad (Hallmark-only and both conditions) perceived less difference in association than those who did not (MetLife-only and baseline), $M=2.94$ versus $M=4.7$, significantly different at $F(1,155)=9.22, p<.05$. Therefore, the Hallmark ad may be slowly closing the 
gap regarding perceived ownership of the Peanuts gang when it advertises, but MetLife's brand schema created by years of advertising is relatively intact.

At the end of the questionnaire, participants were asked to choose whether MetLife or Hallmark was more associated with Snoopy and the gang ("Choice for Snoopy Ownership"). MetLife won the battle most of the time: Overall, 92\% of respondents chose MetLife over Hallmark, significant at $\chi^{2}=$ $218, d f=1, p<.05$. However, there was a significant decrease in choosing MetLife, $96 \%$ in the baseline versus $86 \%$ in the Hallmark-only condition, the condition where MetLife did not advertise at all, $\chi^{2}=$ 3.73, $d f=1, p<.05$, demonstrating that MetLife can be hurt if it does nothing to sustain its association to Snoopy and the gang.

\section{$\underline{\text { Discussion }}$}

The purpose of this study was to investigate whether source confusions would occur for brands using a similar message strategy, and if they did occur, would they favor the brand with the longstanding relationship to the message strategy, or perhaps benefit another well-known brand? We found that, as hypothesized, source confusions did occur when Hallmark used a similar strategy as MetLife in their advertising. Consumers confused this new user's message content and wrongly attributed seeing the Snoopy and the Charlie Brown gang advertisement to the established user, MetLife. It is interesting to note that the long-standing usage of MetLife's commercial even got some consumers to believe they had recently seen a MetLife commercial when they had not, as demonstrated in the false recognition in the baseline condition where no Snoopy advertising was seen.

Rather than hurting MetLife, the Hallmark ads appear to aid consumer memory for the MetLife ads, so that the existing company benefits in two ways from the confusion: It receives credit for the new user's ad and consumers have better memory for the existing company's commercial (Burke and Srull 1988; Campbell and Keller 1999). This finding is consistent with past research that finds repetition of similar competitor claims can increase memory for the general claim - that is, association to Snoopybut also increase confusion as to who is associated with the claim (Law 2002). This confusion is most likely to occur when consumers are not processing the ads at a deep level (Law 2002), as in this more natural viewing environment.

We found that many participants had a strong connection between MetLife and their childhood, reporting remembering Snoopy being MetLife's spokesperson during their early years, and associating Snoopy and the Charlie Brown gang to MetLife. Such findings provide additional evidence in support of Hypothesis 2, the importance of establishing the brand schema early. For instance, one participant said, 
"I remember MetLife commercials like the one we saw growing up," while another said, "The commercial I just watched (MetLife) reminded me of it from when I was a kid."

\section{General Discussion}

The purpose of this research investigation was to determine whether a consistent advertising campaign begun in our participants' early childhood would create a strong brand schema resistant to interference. We were also interested in whether early exposure to the campaign or just the mere repetition of the ads was critical to this schema development process. We found both indirect and direct evidence in our survey that childhood exposure is important for creating positive feelings of warmth, affect, and attitude toward the brand (more implicit measures of memory), as well as for creating explicit memories of seeing the commercials as a child. In our experimental investigation, we found that the strong brand schema created through years of advertising results in source confusions when another company attempts to use a similar message strategy. The established brand is favored when such source confusions occur, resulting in participants believing that they had seen that company's ad when in fact they had not been exposed to it. These results have implications for those interested in studying advertising effects beyond the laboratory situation when prior knowledge comes into play, as well as for advertisers interested in establishing a relationship with consumers at an early age. In addition, there are some implications for managers studying the strength of a brand schema in terms of measures or experiments. We conclude by discussing some areas for future research and limitations of the present research design.

\section{Implications for Advertising Research}

To test a given ad's effectiveness, researchers prefer to assume a "blank slate" —what consumers gain from the advertising is clue solely to what was learned during its presentation. Recall or recognition of an ad is thus thought to be based on what consumers are exposed to during the test session. Yet background knowledge can interact with the ad's message, and memory of the ad, as demonstrated in this study, which may put into question the applicability of laboratory studies for advertising (McQuarrie 1998). Very often, academic researchers attempt to reduce this background knowledge effect by using fictitious brands or advertisements in their studies. These knowledge structures, or schemas, are important for how the ad is perceived, remembered, and used in creating equity in the marketplace. Had we not considered, for instance, that MetLife had had a long history of using the Snoopy characters we might have interpreted the better recall and recognition for its 
commercial as being attributable to superior design rather than its long history. But we also might have wondered why Hallmark's commercial increased associations between the brand and associations to Snoopy, whereas the MetLife one did not.

It is not appropriate to consider memory for an advertisement as being independent from other information in memory. Nor is it appropriate to use the "old" view of memory as a computer metaphor, where information is either accessible or inaccessible from permanent storage. This and other studies have found that a broader view of memory is needed to examine how advertising works (see Hall 2002). This research in particular has demonstrated the dynamics of memory-how certain events, such as childhood exposure, can remain relatively permanent and influential, whereas others, such as source information, can be easily fallible. The schematic view of memory embraces both these results: Early childhood exposure is critical in creating the brand schema, and schematic processes, though highly efficient, can lead to false memories. Advertising factors such as repetition and distinctiveness, which can strengthen the linkages in the brand schema, ought to be considered when developing an advertising campaign.

\section{Establishing an Early Relationship with Consumers}

Although it may not have intended to, MetLife drew children's attention early in life to its advertising with the use of Peanuts characters. It is quite possible that the long-term effects of its advertising are due to the usage of the cartoons. Those in the antismoking advertising arena have claimed that cartoon characters can inappropriately influence young consumers. It is alleged that such usage can be effective, as evidenced by the infamous usage of Joe Camel, which, according to some, increased share of the underage market for Camel cigarettes (DiFranza et al. 1991; Mizerski 1995). It is also noted that personification of the brand through a character is one way to establish a brand relationship (Fournier 1998; Martin 1998), and others have found that it is easy for children to identify with cartoon characters and form relationships with them (DiFranza et al. 1991; Fisher et al. 1991).

Appealing to children for an adult product raises some ethical issues. The Federal Trade Commission struck down "host selling" many years ago for fear that influential childhood program hosts, such as Bozo the Clown, Captain Kangaroo, and other hosts might exert undue influence on children's choice behavior, both during their childhood and later in their adulthood. The effects of an advertisement featuring child-friendly characters on children's future consumption had not yet been addressed (Mizerski 1995). This study demonstrates that early exposure to adult-oriented products can create preferences later in life, as suggested by prior research (Thorson 1990). 
MetLife helped reinforce the early relationship to GenXers through its years of advertising, creating a strong implicit association between Snoopy and the Charlie Brown gang and MetLife. The current campaign using these cartoon characters, which harkens back to when consumers were exposed to the brand during their childhood years, has led to a nostalgic feeling toward MetLife. The nostalgic aspect of MetLife's campaign allows consumers to perceive that they have had a long history with the brand, which can form the underpinnings of a potential relationship (Martin 1998).

In 1965, the Charlie Brown Christmas specials began airing, and Thanksgiving and Halloween specials made their debut soon after. Baby boomers, who had also grown up with the Charlie Brown comic strip, naturally showed some nostalgia when the characters were featured in the MetLife campaign. However, it is noteworthy that the strong relationship between childhood and present-day attitudes and behavior toward MetLife held only for those exposed to the MetLife advertising during their childhood. Although boomers also learned of MetLife's association to Snoopy and the gang through repetition (though not to the same extent as GenXers), for them, that association did not carry the same affect. As hypothesized, early childhood exposure to advertising will lead to greater affect toward the brand, ceteris paribus.

\section{Managerial Implications}

Licensing a cartoon character or signing a spokesperson may entitle the owner to exclusivity within the product category, but not absolute usage. This research is important for managers interested in how multicompany usage of characters and spokespeople (like Michael Jordan) can affect their brand image (Erdogan, Baker, and Tagg 2001). Past academic research on competitive interference mostly involved products within the same category. The most notorious examples of source confusions do involve products in the same category, as in the case of the Energizer bunny. The present research expands the domain for interference, demonstrating that it can occur across categories when a similar message or spokesperson is used.

Using an established spokesperson or character has the advantage of having an already welldefined schema. Whether or not this rich memory network benefits the advertiser depends on how well a linkage between the brand and the spokesperson can be created. We would suggest that the company considering acquiring a highly used person (or character) first conduct an experiment similar to the one conducted here; if the person (or character) causes false memories or source confusions with another brand, then seek another spokesperson. The same can be generalized to testing aspects of brand equity; 
if a company truly "owns" something, then they should be less resistant to competitors' (or others') attacks on that element.

The advantage of having a well-developed brand schema may not be immediately apparent with traditional research methods where attitudes or advertising memory are tested. The indirect experimental method described here is one means to test the strength of the schema; other implicit measures such as software or physiological devices might also be effective. It is noteworthy that MetLife stopped its long-standing Peanuts-animated commercials the summer after this study, reducing those characters' involvement in the advertising to merely a tag line. The new campaign is called "Have you met life today?" and is more focused on product offerings and benefits. We suspect that MetLife might not have realized the impact that its long-standing campaign with Snoopy has had on a new generation of potential customers. According to Barbara Willis, MetLife's assistant vice president of advertising, "The insurer wants to make sure consumers are familiar with its history and its products ... research showed that MetLife was being looked at as 'Snoopy's company'" (Goch 1999). But is that association such a bad thing? Our research reported a strong link between Snoopy and present-day attitudes. Advertising Age columnist Bob Garfield-who say's he'll "go to his grave thinking using Snoopy in the first place was a rotten idea"-questions moving Snoopy from the limelight. "The reason Snoopy was used was because of the public's perception of insurance as a distant, monolithic, soul-less industry ready to steal your money. Snoopy was one way to soften that image," Garfield said. "But complaining that you're the Snoopy company is like climbing Mount Everest and saying it's cold up here and you can't breath" (Goch 1999). As the experiment demonstrated, MetLife has a strong association to Snoopy, but it is not absolute: It needs to be reinforced over time or competitors (or even noncompetitors) can risk shifting the consumer mindspace.

There has been a realization in the marketing arena that brands aren't built in a month or two of advertising (Kotler 1991) but, rather, are years in the making. The move from a short-term to long-term outlook has formed the underpinnings of the relationship-marketing paradigm. When a consumer has a particularly strong relationship to a brand, he or she can move beyond preference to the formation of a strong emotional attachment (Fournier 1998). The present research both reinforces the importance of consistency in maintaining the relationship and suggests that marketers might benefit from beginning the relationship early in the consumer's life. 


\section{Future Research and Limitations}

While future research should delve more deeply into the nature of the thought process and neural networks (Zaltman 1997) associated with near lifelong exposure to brand characters, the present research applications are clear for basic research/theory development as well as for application-focused inquiry. Ideally, one would want to track how much exposure each participant in the study had had with MetLife's advertising as a means to profile and explore the subtleties of consumer memory formation. Future research might consider tracking a product with a long-standing campaign that is not childfriendly to see whether the effects observed here resulted from the use of the warm cartoon characters or from frequent exposure at a critical development period. Unfortunately, because companies change their campaigns so often, this is easier said than done. This research represented a unique snapshot of one company's long-term strategic impact on consumers' memory.

\section{References}

Alba, Joseph W., and Amitava Chattopadhyay (1986), "Salience Effects in Brand Recall," Journal of Marketing Research, 23 (November), 363-369.

, Wesley Hutchinson, and John E. Lynch (1991), "Memory and Decision Making," in Handbook of Consumer Behavior, 1st ed., Thomas S. Robertson and Harold H. Kassarjian, eds., Englewood Cliffs, NJ: Prentice Hall, 1-49.

Braun, Kathryn A. (1999), "Post-Experience Effects on Consumer Memory," Journal of Consumer Research, 25 (March), 319 - 334.

Burke, Raymond, and Thomas Srull (1988), "Competitive Interference and Consumer Memory for Advertising," Journal of Consumer Research, 15 (June), 55-68.

Cacioppo, John T., and Richard M. Petty (1979), "Effects of Message Repetition and Position on Cognitive Responses, Recall and Persuasion, "Journal of Personality and Social Psychology, 37, 97-109.

Campbell, Margaret C, and Kevin Lane Keller (1999), "The Moderating Effect of Brand Knowledge on Advertising Repetition Effects," working paper, Marketing Department, University of California, Los Angeles.

Collins, Allan M., and Elizabeth F. Loftus (1975), "A Spreading- Activation Theory of Semantic Memory," Psychological Review, 82, 407-428.

_ and M. Ross Quillian (1969), "Retrieval Time from Semantic Memory," Journal of Verbal Learning and Verbal Behavior, 8, 240-224. 
Derscheid, Linda E., Yoon-Hee Kwon, and Shi-Ruei Fang (1 996), "Preschoolers' Socialization as Consumers of Clothing and Recognition of Symbolism," Perceptual and Motor Skills, 82 (June), 1171-1181.

DiFranza, Joseph D., John W. Richards, Paul M. Freeman, Nancy Wolf-Gillespie, Christopher Fletcher, Robert D. Jaffe, and David Murray (1991), "RJR Nabisco's Cartoon Camel Promotes Cigarettes to Children," Journal of the American Medical Association, 266(22), 3149-3153.

Edell, Julie (1993), "Advertising Interactions: A Route to Understanding Brand Equity," in Advertising Exposure, Memory and Choice, Andrew S. Mitchell, ed., Hillsdale, NJ: Erlbaum, 195-208.

_ "Journal of Marketing Research, 26,149-163.

Erdogan, B. Zafer, Michael J. Baker, and Stephen Tagg (2001), "Selecting Celebrity Endorsers: The Practitioner's Perspective," Journal of Advertising Research, 3 (May/June), 39-48.

Fisher, Paul M., Meyer D. Schwartz, John W. Richards, Adam O. Goldstein, and Tina H. Rojas (1991), "Brand Logo Recognition by Children Aged Three to Six Yeats, "Journal of the American Medical Association, 266 (22), 3145-3148.

Fournier, Susan (1998), "Consumers and Their Brands: Developing Relationship Theory in Consumer Research," Journal of Consumer Research, 24 (March), 34.3-373.

Goch, Lynna (1999), "Name That Brand," The Collaborative Web site, Industry Publications, www.thecollaborative.com/html/ pubs/branding.cfm (accessed April 15, 2004).

Hall, Bruce F. (2002), "A New Model for Measuring Advertising Effectiveness," Journal of Advertising Research, 42 (March/ April), 23-31.

Haynes, Janice, Diane C. Burts, Alice Dukes, and Rinn Cloud (1993), "Consumer Socialization of Preschoolers and Kindergartners as Related to Clothing Consumption," Psychology and Marketing, 10 (March/April), 151-166.

Holbrook, Morris B., and Robert M. Schindler (1996), "Market Segmentation Based on Age and Attitude Toward the Past: Concepts, Methods, and Findings Concerning Nostalgic Influences on Customer Tastes, "Journal of Business Research, 37 (September), 27-39.

Johar, Gita Venkataramani, and Michel Tuam Pham (1999), "Relatedness, Prominence, and Constructive Sponsor Identification, "Journal of Marketing Research, 36 (August), 299-312.

Johnson, Marcia K., Shahin Hashtroudi, and D. Stephen Lindsay (1993), "Source Monitoring," Psychological Bulletin, 114 (July), 3-28. 
Keller, Kevin Lane (1987), "Memory Factors in Advertising: The Effect of Retrieval Cues on Brand Evaluations, "Journal of Consumer Research, 1.4 (December), 316-333.

(1991), "Memory and Evaluation Effects in Competitive Advertising Environments, "Journal of Consumer Research, 17 (March), 463-476.

_ (1993), "Memory Retrieval Factors and Advertising Effectiveness," in Advertising Exposure, Memory and Choice, Andrew S. Mitchell, ed., Hillsdale, NJ: Erlbaum, 11-48.

Kent, Robert J., and Chris T. Allen (1994), "Competitive Interference Effects in Consumer Memory for Advertising: The Role of Brand Familiarity," Journal of Marketing, 58 (July), 97 - 105.

Kotler, Philip (1991), "Philip Kotler Explores the New Marketing Paradigm," MSI Review (Spring), 4-5. Kotre, John (1995), White Gloves: How We Create Ourselves Through Memory, New York: Free Press. Law, Sharmistha (1995), "Belief in Imitator Claims: The Role of Source Memory," in Advances in Consumer Research, vol. 22, Frank R. Kardes and Mita Sujan, eds., Provo, UT: Association for Consumer Research.

_ (2002), "Can Repeating a Brand Claim Lead to Memory Confusion? The Effects of Claim Similarity and Concurrent Repetition," Journal of Marketing Research, 39 (August), 366-378.

Liesse, Julie (1990), "Bunny Back to Battle Duracell," Advertising Age, 61 (September 17), 4.

Macklin, M. Carole (1985), "Do Young Children Understand the Selling Intent of Commercials?" Journal of Consumer Affairs, 19 (Winter), 293-304.

Martin, Charles L. (1998), "Engineering High-Meaning, High- Involvement Brands as a Relationship Marketing Strategy," Journal of Product Management, 7 (1), 6-26.

McQuarrie, Edward F. (1998), "Have Laboratory Experiments Become Detached from Advertiser Goals?" Journal of Advertising Research, 38 (6), 15-25.

Mitchell, Andrew A., and Jerry C. Olson (1981), "Are Product Attribute Beliefs the Only Mediator of Advertising Effects on Brand Attitudes?" Journal of Marketing Research, 18, 318-332.

Mizerski, Richard (1995), "The Relationship Between Cartoon Trade Character Recognition and Attitude Toward Product Category in Children," Journal of Marketing, 59 (October), 58-70.

Neelankavil, James P., John V. O'Brien, and Richard Tashjian (1985), "Techniques to Obtain MarketRelated Information from Very Young Consumers," Journal of Advertising Research, 25 (June/July), 41-48.

Pham, Michel Tuan, and Gita Venkataramani Johar (1997), "Contingent Processes of Source Identification," Journal of Consumer Research, 24 (December), 249-265.

Schacter, Daniel L. (1996), Searching for Memory, New York: Basic Books. 
Schumann, David W., Richard E. Petty, and D. Scott demons (1990), "Predicting the Effectiveness of Different Strategies of Advertising Variation: A Test of the Repetition Variation Hypotheses," Journal of Consumer Research, 17 (September), 192-202.

Thorndyke, Perry W. (1984), "Applications of Schema Theory in Cognitive Research," in Tutorials in

Teaming and Memory, John R. Anderson and Stephen M. Kosslyn, eds., San Francisco: W.H.

Freeman, 167-192.

Thorson, Esther (1990), "Consumer Processing of Advertising," in Current Issues and Research in

Advertising, vol. 12, James Leigh and Claude Martin, eds., Ann Arbor: University of Michigan, 197-230.

Wilcox, Clyde, Lee Sigelman, and Elizabeth Cook (1989), "Some Like It Hot: Individual Differences in Response to Group Feeling Thermometers," Public Opinion Quarterly, 53 (Summer), 246-258.

Zajonc, Robert B. (1968), "Attitudinal Effects of Mere Exposure," Journal of Personality and Social Psychology, 9 (Monograph Supplement), 1-27.

Zaltman, Gerald (1997), "Rethinking Market Research: Putting People Back $|t|$ " Journal of Marketing Research, 34 (November), 424-437.

\section{Appendix 1}

\begin{tabular}{|c|c|c|c|c|c|}
\hline \multicolumn{6}{|c|}{ Advertising Memory } \\
\hline & Baseline & $\begin{array}{l}\text { MetLife } \\
\text { only }\end{array}$ & $\begin{array}{l}\text { Hallmark } \\
\text { only }\end{array}$ & $\begin{array}{l}\text { Both- } \\
\text { Hallmark first }\end{array}$ & $\begin{array}{l}\text { Both- } \\
\text { MetLife first }\end{array}$ \\
\hline Recall MetLife & n.a. & $78 \%$ & $3 \%$ & $81 \%$ & $83 \%$ \\
\hline Recall Hallmark & n.a. & n.a. & $56 \%$ & $33 \%$ & $37 \%$ \\
\hline Recognize MetLife & $10 \%$ & $86 \%$ & $10 \%$ & $82 \%$ & $82 \%$ \\
\hline Recognize Hallmark-Snoopy & $3 \%$ & $0 \%$ & $56 \%$ & $39 \%$ & $41 \%$ \\
\hline Recognize Hallmark - Carebear & $0 \%$ & $0 \%$ & $6 \%$ & $9 \%$ & $10 \%$ \\
\hline Order in recall-Met first & n.a. & n.a. & n.c. & $52 \%$ & $100 \%$ \\
\hline \multicolumn{6}{|l|}{$\begin{array}{l}\text { Recall Snoopy in MetLife ad } \\
\text { (of participants who had }\end{array}$} \\
\hline recalled that commercial) & n.a. & $\begin{array}{c}96 \% \\
(n=29)\end{array}$ & $\begin{array}{c}3 \% \\
(n=1)\end{array}$ & $\begin{array}{c}96 \% \\
(n=24)\end{array}$ & $\begin{array}{c}96 \% \\
(n=27)\end{array}$ \\
\hline $\begin{array}{l}\text { Recall Snoopy in Hallmark ad } \\
\text { (of participants who recalled } \\
\text { that commercial) }\end{array}$ & n.a. & n.a. & $\begin{array}{c}59 \% \\
(n=17)\end{array}$ & $\begin{array}{c}63 \% \\
(n=11)\end{array}$ & $\begin{array}{c}81 \% \\
(n=11)\end{array}$ \\
\hline Note: n.a. = not available. & & & & & \\
\hline
\end{tabular}




\section{Appendix 2}

Childhood and Present-Day Associations

\begin{tabular}{|c|c|c|c|c|}
\hline & Baseline & MetLife only & Hallmark only & Both \\
\hline \multicolumn{5}{|l|}{ Free association of Snoopy with childhood } \\
\hline MetLife & $80 \%$ & $83 \%$ & $83 \%$ & $83 \%$ \\
\hline Hallmark & $7 \%$ & $8 \%$ & $26 \%$ & $28 \%$ \\
\hline \multicolumn{5}{|l|}{ Identification of Snoopy with childhood } \\
\hline $\begin{array}{l}\text { MetLife } \\
\text { Hallmark }\end{array}$ & $\begin{array}{l}84 \% \\
50 \%\end{array}$ & $\begin{array}{l}92 \% \\
40 \%\end{array}$ & $\begin{array}{l}93 \% \\
76 \%\end{array}$ & $\begin{array}{l}89 \% \\
62 \%\end{array}$ \\
\hline \multicolumn{5}{|l|}{$\begin{array}{l}\text { Strength of association between brand } \\
\text { and Snoopy }(1=\text { not at all; } 10=\text { very much })\end{array}$} \\
\hline MetLife & 8.90 & 8.75 & 8.43 & 8.81 \\
\hline Hallmark & 3.90 & 4.27 & 6.06 & 5.59 \\
\hline \multicolumn{5}{|l|}{ Choice for Snoopy ownership } \\
\hline Number choosing MetLife over Hallmark & $96 \%$ & $92 \%$ & $86 \%$ & $92 \%$ \\
\hline
\end{tabular}

